\title{
Discrimination of matrix-fibre interactions in all-cellulose nanocomposites
}

\author{
T. Pullawan, A.N. Wilkinson, S.J. Eichhorn* \\ School of Materials and The Northwest Composites Centre, Paper Science Building, Sackville Street, University of Manchester, Manchester, M60 4QD, UK
}

\section{A R T I C L E I N F O}

\section{Article history:}

Received 23 June 2010

Received in revised form 21 September

2010

Accepted 25 September 2010

Available online 20 October 2010

\section{Keywords:}

A. Nanocomposites

A. Fibres

B. Interface

C. Stress-transfer

D. Raman spectroscopy

\begin{abstract}
A B S T R A C T
All-cellulose nanocomposites are produced using dissolved microcrystalline cellulose (MCC) as the matrix and cellulose nanowhiskers (CNWs), produced by acid hydrolysis, as the reinforcement. These nanocomposites are then characterised using X-ray diffraction to determine their crystallinity, and Raman spectroscopy to discriminate the reinforcing phase (cellulose I) from the CNWs and the matrix phase (cellulose II) from the dissolved MCC. Mechanical testing of the composites shows that there is a significant systematic reinforcement of the matrix material with the addition of CNWs. Furthermore, Raman spectroscopy is used to show that distinct spectroscopic bands for each phase within the composite spectrum can be used to discriminate the effects of both reinforcement and matrix. It is shown that a Raman band located approximately at $1095 \mathrm{~cm}^{-1}$ can be used to follow the micromechanical deformation of the CNWs and matrix, whereas another band located at $895 \mathrm{~cm}^{-1}$ arises purely from the matrix. This spectroscopic fingerprint is used to gain insights into the complex interactions occurring in these potentially recyclable composite materials, and offers a way forward to optimising their properties.
\end{abstract}

(c) 2010 Elsevier Ltd. All rights reserved.

\section{Introduction}

Cellulose is an abundant and cheap resource that can be used for a wide variety of applications; traditionally in the timber industry for construction, papermaking and for textiles. In recent times cellulose fibres have been widely reported as a possible replacement for glass fibres in composite materials, due to their comparatively lower weight, cost and for the fact that they are easier to process [1]. The mechanical properties of cellulose fibres (typically extracted from plant material, either by chemical and/or mechanical means) are known to be variable, due to growing conditions, the environment in which they are tested and damage that can occur during extraction [2]. In particular, the defects that occur in the cell walls of plant fibres are known to be sources of local stress concentrations, which can lead to premature failure and low fracture toughness of natural fibre composites [3,4]. In recent times, cellulose nanofibres (in the form of whiskers, fibrils, etc.) have been reported as possible ways to overcome the natural variability of plant fibres $[5,6]$. The concept is that the plant fibres can be broken down into nanosized constituent fibrous components, either by mechanical or chemical treatment. Nanofibres of cellulose that are generated by mechanical means are usually referred to as Microfibrillated Cellulose (MFC), a term that was originally coined by Turbak et al. [7]. They are generally long fibrils of cellulose and have been studied widely in terms of their reinforcement capabil-

\footnotetext{
* Corresponding author. Tel.: +44 (0) 161306 5982; fax: +44 (0) 1613063586

E-mail address: s.j.eichhorn@manchester.ac.uk (S.J. Eichhorn).
}

ity $[8,9]$. Chemical hydrolysis of plant cellulose can produce whiskers of material (sometimes called cellulose nanocrystals but herein referred to as cellulose nanowhiskers (CNWs)). These CNWs were first discovered by Ranby and Noe [10], and subsequently Revol et al. [11] showed how they could undergo chiral nematic ordering in suspension. A form of CNWs can be extracted from the tunicate sea squirt (Halocynthia roretzi) [12], and have also been reported to be efficient reinforcement materials in nanocomposites owing to their ability to form percolated networks [13-15].

Most cellulose fibre-based composites comprise two dissimilar phases; namely the reinforcement (fibre) and matrix phases. Typically the latter is a synthetic polymer; which raises issues when it comes to end-of-life use, particularly if recycling of the material is required. In recent times a new form of composite has been developed, whereby the matrix is reinforced with a fibre of the same material, thereby overcoming recycling issues. These all-polymer composites were initially developed through the pioneering work of Ward and colleagues at the University of Leeds, who first reported a method of hot-compacting polyethylene fibres into a single-phase composite [16]. Subsequently a large body of work has been completed in this area by this group and others, resulting in many commercial products; a review of which is beyond the scope of this article. A forerunner to the development of all-cellulose composites was the work of Glasser et al. [17-19], who reinforced a cellulose ester (cellulose acetate butyrate) matrix using regenerated cellulose fibres. Subsequently Gindl and Keckes [20] reported the reinforcement of a cellulose acetate butyrate matrix using bacterial cellulose. It was, however, Nishino et al. [21] who first used the expression "all-cellulose composite" when they reported 
remarkable reinforcement upon incorporating ramie fibres in a dissolved cellulose matrix material derived from Kraft pulp (dissolved in a solvent of $\mathrm{LiCl} / \mathrm{DMAc}$ - lithium chloride and dimethylacetamide). Subsequently, Gindl and Keckes showed self-reinforcement in a composite material using partially dissolved microcrystalline cellulose [22]. After this pioneering work, a large number of papers have been published on all-cellulose composites [21-31], typically produced by dispersing fibres into dissolved matrix materials derived from a variety of sources. Some fundamental work has been undertaken on the interaction between the matrix and fibre phases in all-cellulose composites using synchrotron $\mathrm{X}$ ray diffraction, whereby the crystallographic orientation of the reinforcing fibre phase could be followed, as distinct from the matrix [23].

In this study, we report the use of a Raman spectroscopic technique to follow the local deformation of an all-cellulose nanocomposite. Raman spectroscopy is a technique that has been used to map the local stress state in a variety of fibre reinforced composites [32]. The technique relies on obtaining a clear and distinct spectrum of an embedded reinforcing phase, typically using a composite with an optically transparent matrix. The position of Raman peaks within this spectrum are found to shift upon the external application of strain to the composite, this shift being related to the direct molecular or structural deformation of the reinforcing fibre. By using a variety of composite geometries, and model fits to data obtained by this approach, a picture of the interfacial behaviour between the reinforcing phase and matrix can be obtained [33-35]. The technique has been applied to cellulose fibre-based composites [36-38] and more recently cellulose nanocomposites [39-41]. We report, for the first time, the use of a Raman spectroscopic technique to discriminate between the deformation behaviour of CNW reinforcement within a cellulose matrix composite.

\section{Experimental}

\subsection{Materials and sample preparation}

Microcrystalline cellulose (MCC) (Avicel, PH-101, Sigma-Aldrich, UK; particle size $\sim 50 \mu \mathrm{m}$ ) was used as the source of the matrix material. The solvent used to dissolve the MCC was lithium chloride ( $\mathrm{LiCl}$ ) (Sigma-Aldrich, UK; anhydrous, $\geqslant 99.0 \%$ ) and N,Ndimethylacetamide (DMAc) (Sigma-Aldrich, UK). Cellulose nanowhiskers (CNWs) were produced by acid hydrolysis of cotton linters (Whatman filter grade, Whatman).

The MCC was activated for $5 \mathrm{~h}$ in distilled water at room temperature to swell the material ready for dissolution. This swollen material was then sequentially dehydrated in acetone and DMAc for $5 \mathrm{~h}$ and $4 \mathrm{~h}$, respectively, before the DMAc was decanted from the dehydrated cellulose. A solution of $8 \mathrm{wt}$.\% of $\mathrm{LiCl}$ in DMAc was then prepared, and stirred at a temperature of $120^{\circ} \mathrm{C}$ for $30 \mathrm{~min}$ until the $\mathrm{LiCl}$ completely dissolved. Then the activated MCC ( $2 \mathrm{~g}$ ) was dissolved in the LiCl/DMAc solution by magnetic stirring at room temperature for $5 \mathrm{~min}$. In order to prepare fully amorphous cellulose, the solution of activated MCC/LiCl/DMAc was stored in a sealed bottle for 1 week to allow full dissolvation.

CNWs were produced from cotton linters using the following process, which has been described elsewhere [40]. The cotton linters $(40 \mathrm{~g})$ were reacted with sulphuric acid $(64 \mathrm{wt} . \%, 700 \mathrm{ml})$ at $45^{\circ} \mathrm{C}$ for $45 \mathrm{~min}$, after which the reaction was quenched using a fivefold dilution. The reaction media was then concentrated and rinsed by centrifugation ( $6000 \mathrm{rpm}, 10 \mathrm{~min}$ ) followed by dialysation against water until neutral $\mathrm{pH}$ conditions were obtained. The suspension was then sonicated, treated with mixed bed ionexchange resin and filtered using glass microfiber filters (Whatman). The concentration of the final suspension was
$2.0 \pm 0.2$ wt.\%. To generate CNWs reinforced composite films, either $0.5 \mathrm{~g}$ or $1 \mathrm{~g}$ (to make either a $0.5 \%$ or $1 \%$ volume fraction composite, respectively) of freeze-dried CNWs were added to the dissolved MCC solution, and then dispersed using ultrasonification. The resultant viscous solution was then poured into a Petri dish and left under ambient conditions for $8 \mathrm{~h}$. After a transparent gel film had formed, this was washed in distilled water, and then dried at $40{ }^{\circ} \mathrm{C}$ for $4 \mathrm{~h}$.

\subsection{X-ray diffraction and Raman spectroscopy}

A powder X-ray diffractometer (Philips X'Pert-MPD) was used to determine the crystallinity of the composite and control samples. Activated MCC powder, CNWs and the composite samples were analysed using $\mathrm{Cu} \mathrm{K} \alpha$ radiation, with a step size of $0.05^{\circ}$ over a $2 \theta$ range of $5-40^{\circ}$. Crystallinity of the samples was determined using Segal's method [42].

Raman spectroscopy was carried out using a Renishaw System 1000 spectrometer coupled to an Olympus BH- 1 microscope fitted with a $50 \times$ lens to focus the output from a $785 \mathrm{~nm}$ near-infrared laser to a 1-2 $\mu \mathrm{m}$ spot on the surface of the samples. The power on the sample was recorded and found to be $1 \mathrm{~mW}$. Spectra were obtained using an exposure time of $600 \mathrm{~s}$.

\subsection{Mechanical testing of composites}

Tensile testing of thin films of the cellulose nanocomposites was performed using an Instron 1121 universal testing machine. A gauge length of $50 \mathrm{~mm}$ and a nominal width of $5 \mathrm{~mm}$ was used for the dimensions of the specimens. Actual specimen dimensions (width and thickness) used to calculate stress were measured using a micrometer. All specimens were equilibrated (for $48 \mathrm{~h}$ prior to testing) and tested under standard conditions of $23 \pm 1{ }^{\circ} \mathrm{C}$ and $50 \pm 5 \%$ relative humidity. Samples were deformed in tension using a cross-head displacement rate of $1 \mathrm{~mm} \mathrm{~min}^{-1}$ and a $500 \mathrm{~N}$ (full scale) load cell was used to record the load.

\subsection{Micromechanical deformation of composites using Raman spectroscopy}

Raman micromechanical deformation studies were performed on individual nanocomposite samples, with gauge lengths of $50 \mathrm{~mm}$, fixed onto a customised deformation rig (Deben, MICROTEST). Spectra were obtained from the nanocomposites during incremental tensile testing on this deformation rig, which fitted directly onto the microscope stage of the Raman spectrometer. The laser beam was polarised parallel to the nanocomposite sample's axis, and an exposure time of $60 \mathrm{~s}$ with two accumulations (total time $=120 \mathrm{~s}$ ), was used to obtain a spectrum at each strain increment $(0.1 \%)$. All samples were deformed until fracture occurred.

\section{Results and discussion}

\subsection{Crystallinity and molecular composition of all-cellulose nanocomposites}

Typical X-ray diffraction patterns for pure CNWs, a nanocomposite of CNWs and MCC dissolved in $\mathrm{LiCl} / \mathrm{DMAC}$ and a pure matrix of MCC dissolved in LiCl/DMAc are reported in Fig. 1. All peaks present for the CNWs are consistent with a cellulose I structure, apart from a peak at $12^{\circ}$. The origin of this peak is unknown. Crystallinities for each of these samples are reported in Table 1. It is clear that the CNWs are highly crystalline ( $85 \%)$. However, the matrix material of MCC dissolved in LiCl/DMAc exhibits low crystallinity $(\sim 26 \%)$. The addition of CNWs to this matrix material in- 


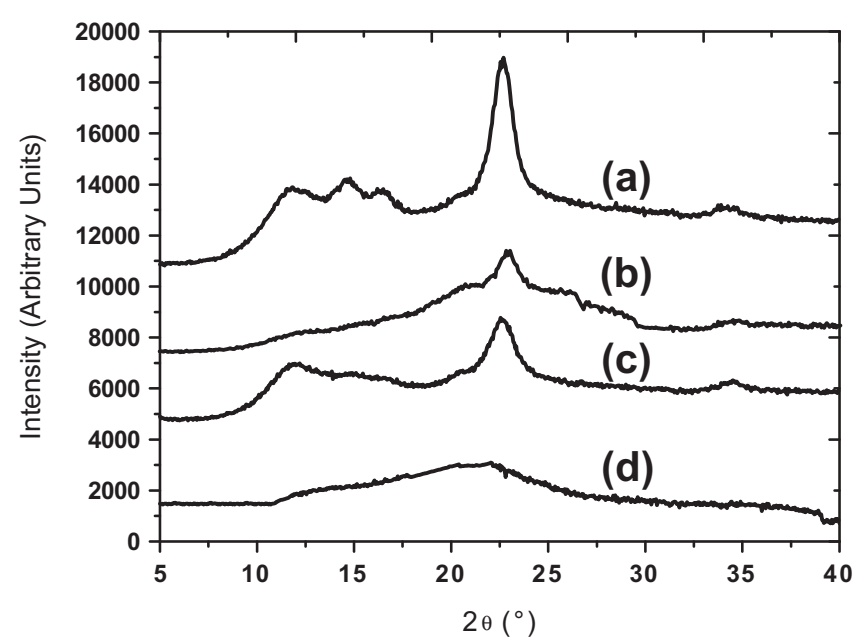

Fig. 1. Typical X-ray diffraction patterns for: (a) CNWs (b) a nanocomposite of activated MCC dissolved in LiCl/DMAc with CNWs (0.5\% volume fraction), (c) a nanocomposite of activated MCC dissolved in $\mathrm{LiCl} / \mathrm{DMAc}$ with CNWs (1.0\% volume fraction) and (d) activated MCC dissolved in LiCl/DMAc.

Table 1

Crystallinity values for cellulose nanowhiskers (CNWs), activated MCC (MCC), activated MCC dissolved in $\mathrm{LiCl} / \mathrm{DMAc}(\mathrm{MCC} / \mathrm{LiCl} /$ DMAc) and two nanocomposite samples $(0.5 \%$ and $1.0 \%$ volume fractions) of activated MCC dissolved in LiCl/DMAc with CNWs (MCC/LiCl/DMAc/CNWs). Standard errors are given as \pm the mean.

\begin{tabular}{ll}
\hline Sample & Crystallinity (\%) \\
\hline CNWs & $85.2 \pm 0.7$ \\
MCC/LiCl/DMAc & $25.8 \pm 0.6$ \\
MCC/LiCl/DMAc/CNWs 0.5\% & $39.7 \pm 0.4$ \\
MCC/LiCl/DMAc/CNWs 1.0\% & $47.7 \pm 0.4$ \\
\hline
\end{tabular}

creases the crystallinity of the samples ( $\sim 40 \%$ and $\sim 48 \%$ at volume fractions of $0.5 \%$ and $1.0 \%$, respectively).

\subsection{Mechanical properties of all-cellulose nanocomposites}

Typical stress-strain curves for all samples are reported in Fig. 2. It is noted that these stress-strain curves are all non-linear. This non-linearity is typical for a regenerated cellulose film, as previously reported for films made using this approach $[43,44]$. The mean mechanical properties data are reported in Table 2 . We note that our films, without the addition of CNWs, have lower mechanical properties than those previously reported by Gindl and Keckes [44]; they reported values in the range $\sim 10-30 \mathrm{GPa}$ and $\sim 200$ $430 \mathrm{MPa}$ for the Young's modulus and tensile strength of drawn films of MCC dissolved in LiCl/DMAc. However, these higher values are probably due to the fact that they applied drawing to their material [43], whilst wet, inducing orientation, whereas our samples are undrawn. Our values are however close to those obtained by Duchemin et al. [45], who also did not draw their samples. This study, however, aims primarily to ascertain the interfacial phenomena that occur in all-cellulose composites, and to provide a means for following this process under a potential range of processing conditions. Therefore we are, at this stage, not aiming to maximise the mechanical properties of our material, but will seek to do so at a later stage.

Adding CNWs to the matrix material enhances the mechanical properties; both the tensile strength and Young's modulus of the nanocomposites increase with increasing CNWs content. With the addition of $1 \%$ CNWs (Table 2), Young's modulus more than doubles and the strength also increases significantly (approxi-

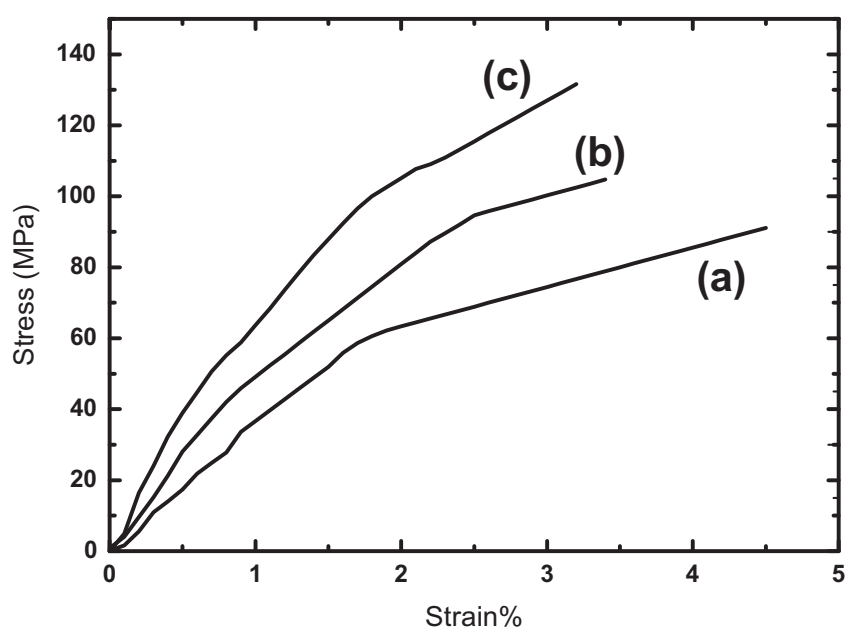

Fig. 2. Typical stress-strain curves for: (a) activated MCC dissolved in LiCl/DMAC and (b) and (c) activated MCC dissolved in LiCl/DMAc with $0.5 \%$ and $1.0 \%$ volume fractions of CNWs respectively.

Table 2

Mechanical properties for activated MCC dissolved in LiCl/DMAc (MCC/LiCl/DMAc) and two nanocomposite samples $(0.5 \%$ and $1.0 \%$ volume fractions) of activated MCC dissolved in $\mathrm{LiCl} / \mathrm{DMAc}$ with CNWs (MCC/LiCl/DMAc/CNWs). Standard errors are given as \pm the mean (in brackets when $<0.1$ ).

\begin{tabular}{lcl}
\hline Sample & $\begin{array}{l}\text { Tensile strength } \\
(\mathrm{MPa})\end{array}$ & $\begin{array}{l}\text { Young's modulus } \\
(\mathrm{GPa})\end{array}$ \\
\hline $\mathrm{MCC} / \mathrm{LiCl} / \mathrm{DMAc}$ & $91.0 \pm 2.4$ & $1.9(0.04)$ \\
$\mathrm{MCC} / \mathrm{LiCl} / \mathrm{DMAc} / \mathrm{CNWs}$ & $111.2 \pm 2.6$ & $3.2(0.04)$ \\
$0.5 \%$ & $128.4 \pm 2.3$ & \\
$\mathrm{MCC} / \mathrm{LiCl} / \mathrm{DMAc} / \mathrm{CNWs}$ & & $4.8 \pm 0.1$ \\
$1.0 \%$ & & \\
\hline
\end{tabular}

mately $41 \%$ ). This reinforcement is thought to be due to the presence of the stiff and strong CNWs a comparatively compliant matrix. A simple method to predict the modulus of a composite is provided by the rule-of-mixtures equation, namely

$E_{\mathrm{c}}=\eta E_{\mathrm{f}} V_{\mathrm{f}}+\left(1-V_{\mathrm{f}}\right) E_{\mathrm{m}}$

where $E_{\mathrm{c}}, E_{\mathrm{f}}$ and $E_{\mathrm{m}}$ are the composite, fibre and matrix moduli respectively, $V_{\mathrm{f}}$ is the volume fraction of the fibre reinforcement, and $\eta$ is an efficiency factor dependent on fibre orientation. Using a value of $100 \mathrm{GPa}$ for the modulus of the CNWs [40] and $E_{\mathrm{m}}=1.9 \mathrm{GPa}$ (see Table 1 ), gives a value of $E_{\mathrm{c}}=2.1 \mathrm{GPa}$ (at $1.0 \%$ volume fraction), assuming an efficiency factor $(\eta)$ of $3 / 8$ (random inplane arrangement of CNWs). Similarly, at a volume fraction of $0.5 \%$ a value of $E_{\mathrm{c}}=2.1 \mathrm{GPa}$ is obtained. Both these values are lower than those observed experimentally. One possible explanation for this disagreement is the development of a percolated network of CNWs forming in the nanocomposites, similar to percolation effects seen in other CNW based nanocomposites [13-15], although more work is required to confirm this. In addition there may be changes to the properties of the matrix induced by the addition of nanoscale reinforcements as a consequence of their large interfacial area. For example, increased levels of crystallinity and/or constrained amorphous chain segments can occur, particularly in systems with strong reinforcement-matrix interactions [46]. The data in Table 1 show that the addition of $1 \%$ by volume of the highly crystalline $(\approx 85 \%)$ CNWs to the MCC matrix, with a degree of crystallinity of just under $26 \%$, results in a nanocomposite with a much higher degree of crystallinity ( $47.7 \%$ ) than the just over $26 \%$ predicted from a simple rule-of-mixtures calculation. 


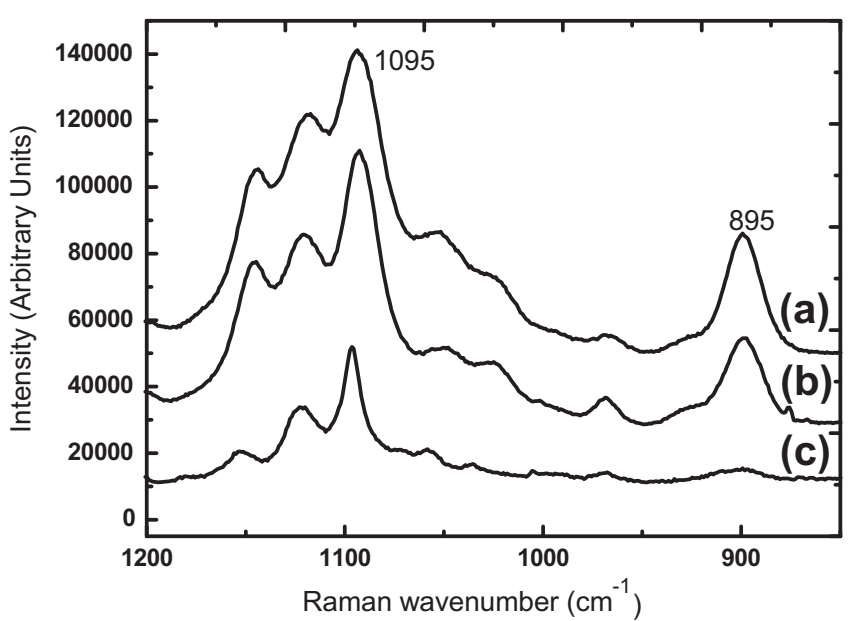

Fig. 3. Typical Raman spectra for: (a) activated MCC dissolved in $\mathrm{LiCl} / \mathrm{DMAc}$, (b) a nanocomposite of activated MCC dissolved in LiCl/DMAc with CNWs (1.0 wt.\%) and (c) pure CNWs.

\subsection{Micromechanics of the interfaces in all-cellulose nanocomposites}

Typical Raman spectra obtained from the pure matrix material and nanocomposites are reported in Fig. 3. There have been numerous assignments of the Raman band located at $1095 \mathrm{~cm}^{-1}$, of which two suggest the $\mathrm{C}-\mathrm{O}$ stretching mode as a possible source of this vibration $[47,48]$. Other assignments have suggested a stretching mode involving the glycosidic linkage (C-O-C) $[49,50]$.

(a)

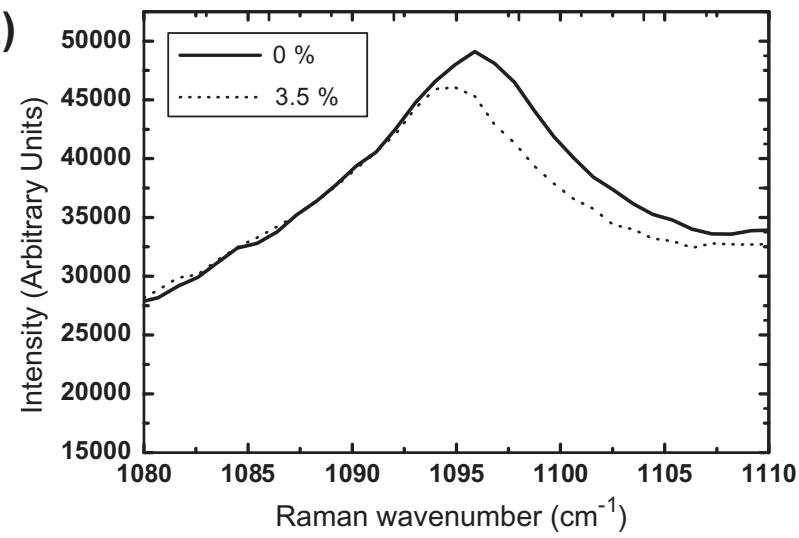

(b)

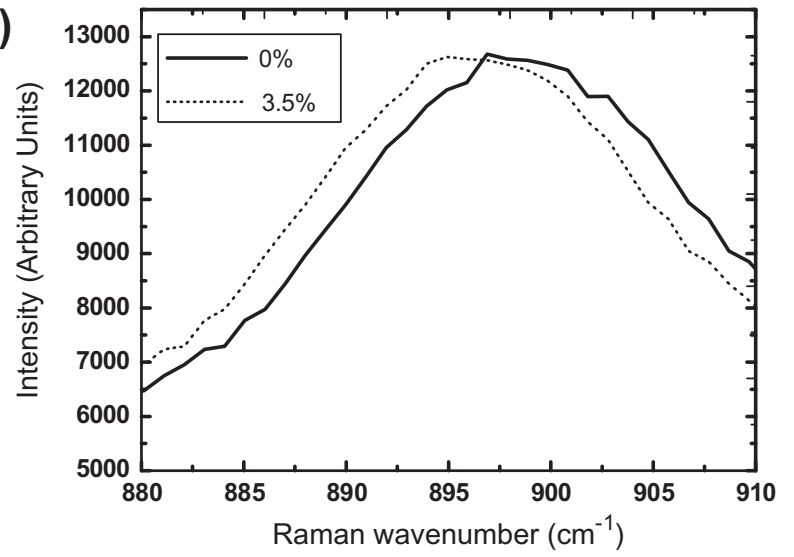

Fig. 4. Typical strain-induced shifts in the peak positions for the Raman bands initially located at approximately: (a) $1095 \mathrm{~cm}^{-1}$ and (b) $895 \mathrm{~cm}^{-1}$.
Atalla and Dimick were the first to show that cellulose I (native plant-based cellulose) has a different Raman spectrum to cellulose II (chemically regenerated form) [51]. These differences were shown to be numerous, particularly in the low-frequency region [51]. Of particular note in the spectra reported by Atalla and Dimick [51] is the absence of a peak at $895 \mathrm{~cm}^{-1}$ for the cellulose I Raman spectrum [51]. The Raman spectrum from the pure matrix material (see Fig. 3a) exhibits both a peak at $1095 \mathrm{~cm}^{-1}$ and $895 \mathrm{~cm}^{-1}$. On the other hand, the Raman spectrum from the CNWs (see Fig. 3c) only exhibits a peak at $1095 \mathrm{~cm}^{-1}$ (as well as other peaks close-by within the same region). This is in agreement with the findings of Atalla and Dimick [51], and so it is clear that the activated MCC (cellulose I) has been regenerated (cellulose II). Furthermore, this distinctive "fingerprint" spectrum from the matrix material makes it possible to isolate matrix and whisker interactions from the nanocomposite spectrum (see Fig. 3b). It should be noted that the Raman peak located at $1095 \mathrm{~cm}^{-1}$ arises from both the matrix and the CNWs, and that it is not possible to fully distinguish the latter from the former component.

Both Raman peaks located initially at $1095 \mathrm{~cm}^{-1}$ and $895 \mathrm{~cm}^{-1}$ exhibited strain-induced shifts towards a lower wavenumber (see Fig. 4). The shift itself is thought to be due to the direct molecular stressing of the backbone of the cellulose polymer [32,52]. A subtle difference between the profiles of the shifts in the Raman peaks located at $1095 \mathrm{~cm}^{-1}$ and $895 \mathrm{~cm}^{-1}$ is also instructive. The Raman
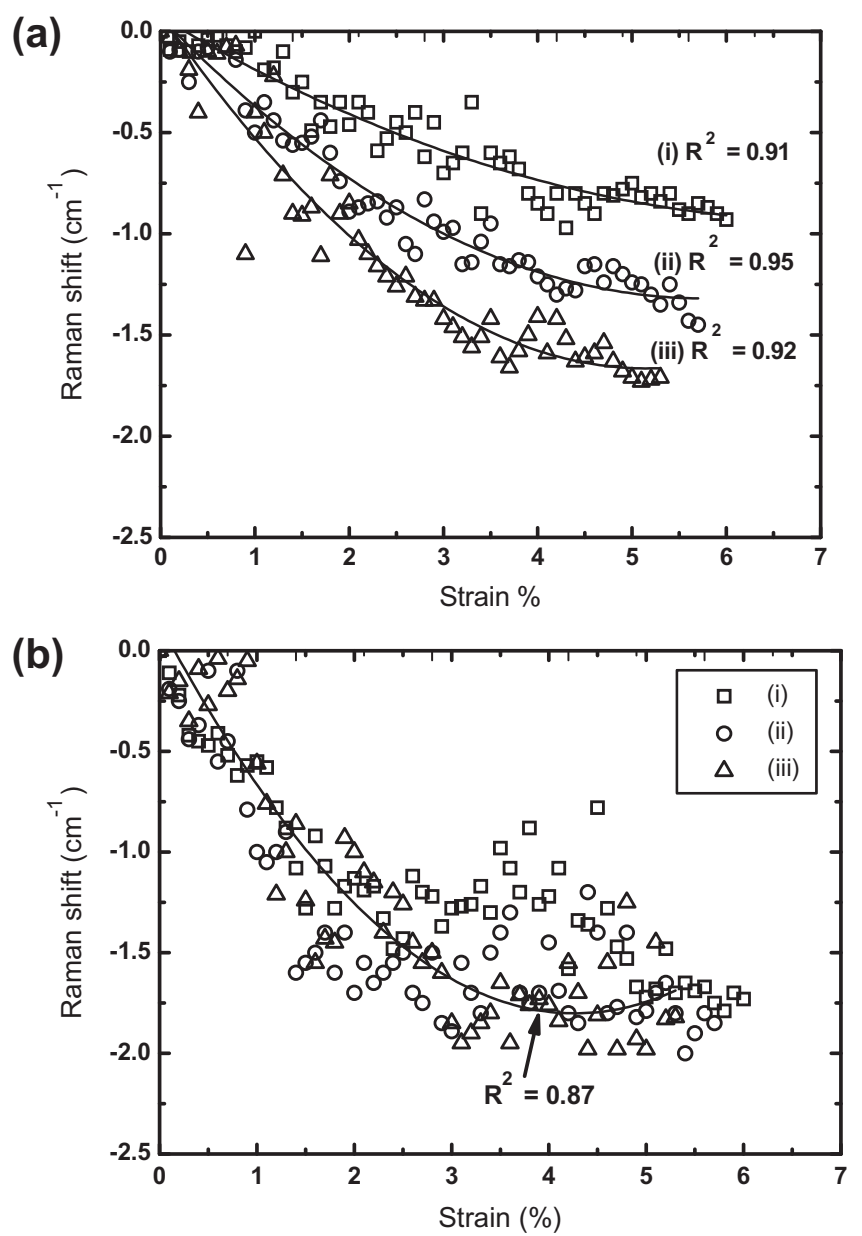

Fig. 5. Shifts in the Raman bands located at: (a) $1095 \mathrm{~cm}^{-1}$ and (b) $895 \mathrm{~cm}^{-1}$ as a function of tensile strain for (i) activated MCC dissolved in LiCl/DMAc and two nanocomposite specimens of activated MCC dissolved in LiCl/DMAc with CNWs; (ii) $0.5 \%$ and (iii) $1.0 \%$ volume fractions. Solid lines are polynomial fits to the data and are a guide for the eye only. 
peak located at $1095 \mathrm{~cm}^{-1}$ appears to not only shift, but to also asymmetrically broaden. Asymmetrical broadening of Raman peaks from stressed cellulosic structures have been previously observed $[53,54]$, and suggested to be due to a non-uniform distribution of stress over the structure. This non-uniform distribution of stress is thought to be evidence of stress-transfer from the matrix to the reinforcing CNWs; the process of reinforcement in composites. No such asymmetric broadening is observed for the Raman band located at $895 \mathrm{~cm}^{-1}$ which further supports this hypothesis; uniform stress being present in the matrix material as this peak arises from this component of the composite alone.

Detailed positional information from the peaks, as a function of tensile strain, is reported in Fig. 5. The profile of the shifts in the position of the Raman band located initially at $1095 \mathrm{~cm}^{-1}$ are non-linear, and reflect the shape of the stress-strain curves shown in Fig. 2. As the volume fraction of CNWs is increased, so the initial shift rate with respect to strain of the Raman band initially located at $1095 \mathrm{~cm}^{-1}$ increases (see Fig. 5a). This systematic increase in the strain-induced shift rate with volume fraction is an indication of the progressive increase in stress-transfer from matrix to the CNWs reinforcement. However, no such progressive increase in the shift rate with respect to strain is noted for the Raman peak located at $895 \mathrm{~cm}^{-1}$, where the data for each sample superimpose onto the same profile (see Fig. 5b). This shows that although there is stress-transfer within the matrix, the improvement in this aspect of the nanocomposites' tensile properties comes from the addition of CNWs, and their interface with the resin material.

\section{Conclusions}

The Raman technique has been proven to be a powerful tool for the study of all-cellulose nanocomposites. Previous studies using Raman spectroscopy to study local deformation micromechanics in composite materials have investigated materials where the matrix and reinforcing phase are dissimilar. It has been shown here however that single-phase composites can also be investigated, by obtaining a "fingerprint" Raman spectrum of the matrix which is distinct from the reinforcing phase. It has been shown that CNWs can be used to reinforce a matrix of activated MCC dissolved in $\mathrm{LiCl} / \mathrm{DMAc}$. An increase in the tensile mechanical properties of the nanocomposites was observed with increasing amounts of CNWs. Shifts in the positions of two Raman peaks, one for the matrix material at $895 \mathrm{~cm}^{-1}$ and another at $1095 \mathrm{~cm}^{-1}$ from both the matrix and CNWs, have been used to follow the local micromechanics of the interface in these materials. This systematic reinforcement is reflected in an increase in the shift rate with respect to strain, obtained from the peak representing the reinforcing phase. This technique is proposed as a possible approach for studying interfaces in all-cellulose composites, and future work will focus on this.

\section{Acknowledgement}

The authors wish to thank the Royal Thai government for providing a Scholarship for T.P. to undertake this research.

\section{References}

[1] Eichhorn SJ, Baillie CA, Zafeiropoulos N, Mwaikambo LY, Ansell MP, Dufresne A, et al. Review: current international research into cellulosic fibres and composites. J Mater Sci 2001;36(9):2107-31.

[2] Davies GC, Bruce DM. Effect of environmental relative humidity and damage on the tensile properties of flax and nettle fibers. Text Res J 1998;68(9):623-9.

[3] Hughes M, Sebe G, Hague J, Hill C, Spear M, Mott L. An investigation into the effects of micro-compressive defects on interphase behaviour in hemp-epoxy composites using half-fringe photoelasticity. Compos Interface 2000;7(1): 13-29.
[4] Hughes M, Hill CAS, Hague JRB. The fracture toughness of bast fibre reinforced polyester composites - part 1 - evaluation and analysis. J Mater Sci 2002;37(21):4669-76.

[5] Eichhorn SJ, Dufresne A, Aranguren M, Marcovich NE, Capadona JR, Rowan SJ, et al. Review: current international research into cellulose nanofibres and nanocomposites. J Mater Sci 2010;45(1):1-33.

[6] Berglund LA, Peijs T. Cellulose biocomposites - from bulk moldings to nanostructured systems. MRS Bull 2010;35(3):201-7.

[7] Turbak AF, Snyder FW, Sandberg KR. Microfibrillated cellulose, a new cellulose product: properties, uses, and commercial potential. J Appl Polym Sci: Appl Polym Symp 1983;37(Proc Cellul Conf, 9th, 1982, Part 2):815-27.

[8] Nakagaito AN, Yano H. Novel high-strength biocomposites based on microfibrillated cellulose having nano-order-unit web-like network structure. Appl Phys A - Mater Sci Process 2005;80(1):155-9.

[9] Henriksson M, Berglund LA, Isaksson P, Lindstrom T, Nishino T. Cellulose nanopaper structures of high toughness. Biomacromolecules 2008;9(6): 1579-85.

[10] Ranby BG, Noe RW. Crystallization of cellulose and cellulose derivatives from dilute solution. 1. Growth of single crystals. J Polym Sci 1961;51(155):337-47.

[11] Revol JF, Bradford H, Giasson J, Marchessault RH, Gray DG. Helicoidal selfordering of cellulose microfibrils in aqueous suspension. Int J Biol Macromol 1992;14(3):170-2.

[12] Ranby BG. Physico-chemical investigations on animal cellulose (tunicin). Arkiv Kemi 1952;4(3):241.

[13] Favier V, Chanzy H, Cavaille JY. Polymer nanocomposites reinforced by cellulose whiskers. Macromolecules 1995;28(18):6365-7.

[14] Capadona JR, Van Den Berg O, Capadona LA, Schroeter M, Rowan SJ, Tyler DJ, et al. A versatile approach for the processing of polymer nanocomposites with self-assembled nanofibre templates. Nat Nanotechnol 2007;2(12):765-9.

[15] Capadona JR, Shanmuganathan K, Tyler DJ, Rowan SJ, Weder C. Stimuliresponsive polymer nanocomposites inspired by the sea cucumber dermis. Science 2008;319(5868):1370-4.

[16] Hine PJ, Ward IM, Olley RH, Bassett DC. The hot compaction of high modulus melt-spun polyethylene fibers. J Mater Sci 1993;28(2):316-24.

[17] Seavey KC, Glasser WG. Continuous cellulose fiber-reinforced cellulose ester composites. II. Fiber surface modification and consolidation conditions. Cellulose 2001;8(2):161-9.

[18] Seavey KC, Ghosh I, Davis RM, Glasser WG. Continuous cellulose fiberreinforced cellulose ester composites. I. Manufacturing options. Cellulose 2001;8(2):149-59.

[19] Franko A, Seavey KC, Gumaer J, Glasser WG. Continuous cellulose fiberreinforced cellulose ester composites III. Commercial matrix and fiber options. Cellulose 2001;8(2):171-9.

[20] Gindl W, Keckes J. Tensile properties of cellulose acetate butyrate composites reinforced with bacterial cellulose. Compos Sci Technol 2004;64(15):2407-13.

[21] Nishino T, Matsuda I, Hirao K. All-cellulose composite. Macromolecules 2004;37(20):7683-7.

[22] Gindl W, Keckes J. All-cellulose nanocomposite. Polymer 2005;46(23): 10221-5.

[23] Gindl W, Martinschitz KJ, Boesecke P, Keckes J. Structural changes during tensile testing of an all-cellulose composite by in situ synchrotron X-ray diffraction. Compos Sci Technol 2006;66(15):2639-47.

[24] Nishino T, Arimoto N. All-cellulose composite prepared by selective dissolving of fiber surface. Biomacromolecules 2007;8(9):2712-6.

[25] Qin C, Soykeabkaew N, Xiuyuan N, Peijs T. The effect of fibre volume fraction and mercerization on the properties of all-cellulose composites. Carbohyd Polym 2008;71(3):458-67.

[26] Soykeabkaew N, Arimoto N, Nishino T, Peijs T. All-cellulose composites by surface selective dissolution of aligned ligno-cellulosic fibres. Compos Sci Technol 2008;68(10-11):2201-7.

[27] Duchemin BJC, Mathew AP, Oksman K. All-cellulose composites by partial dissolution in the ionic liquid 1-butyl-3-methylimidazolium chloride. Compos Part a - Appl Sci Manuf 2009;40(12):2031-7.

[28] Soykeabkaew N, Nishino T, Peijs T. All-cellulose composites of regenerated cellulose fibres by surface selective dissolution. Compos Part a - Appl Sci Manuf 2009;40(4):321-8.

[29] Soykeabkaew N, Sian C, Gea S, Nishino T, Peijs T. All-cellulose nanocomposites by surface selective dissolution of bacterial cellulose. Cellulose 2009;16(3):435-44.

[30] Zhao Q, Yam R, Zhang BQ, Yang YK, Cheng XJ, Li R. Novel all-cellulose ecocomposites prepared in ionic liquids. Cellulose 2009;16(2):217-26.

[31] Arevalo R, Picot OT, Wilson RM, Soykeabkaew N, Peijs T. All-cellulose composites by partial dissolution of cotton fibres. J Biobased Mater Bioenergy 2010;4(2):129-38.

[32] Young RJ, Eichhorn SJ. Deformation mechanisms in polymer fibres and nanocomposites. Polymer 2007;48(1):2-18.

[33] Day RJ, Young RJ. Raman microscopy of fibers and composites. J Microsc Oxford 1993;169:155-61.

[34] Young RJ, Huang YL, Gu X, Day RJ. Analysis of composite test methods using Raman-spectroscopy. Plast Rub Compos Proc Appl 1995;23(1):11-9.

[35] Young RJ. Evaluation of composite interfaces using Raman spectroscopy. Key Eng Mater 1996;116:173-92.

[36] Eichhorn SJ, Young RJ. Deformation micromechanics of natural cellulose fibre networks and composites. Compos Sci Technol 2003;63(9):1225-30.

[37] Eichhorn SJ, Young RJ. Composite micromechanics of hemp fibres and epoxy resin microdroplets. Compos Sci Technol 2004;64(5):767-72. 
2330

T. Pullawan et al./Composites Science and Technology 70 (2010) 2325-2330

[38] Tze WTY, O’Neill SC, Trips CP, Gardner DJ, Shaler SM. Evaluation of load transfer in the cellulosic-fiber/polymer interphase using a micro-Raman tensile test. Wood Fiber Sci 2007;39(1):184-95.

[39] Sturcova A, Davies GR, Eichhorn SJ. Elastic modulus and stress-transfer properties of tunicate cellulose whiskers. Biomacromolecules 2005;6(2): 1055-61.

[40] Rusli R, Eichhorn SJ. Determination of the stiffness of cellulose nanowhiskers and the fiber-matrix interface in a nanocomposite using Roman spectroscopy. Appl Phys Lett 2008;93(3):3.

[41] Rusli R, Shanmuganathan K, Rowan SJ, Weder C, Eichhorn SJ. Stress-transfer in anisotropic and environmentally adaptive cellulose whisker nanocomposites. Biomacromolecules 2010;11(3):762-8.

[42] Segal L, Creely JJ, Martin Jr AE, Conrad CM. An empirical method for estimating the degree of crystallinity of native cellulose using the X-ray diffractometer. Text Res J 1959;29(10):786-94.

[43] Gindl W, Martinschitz KJ, Boesecke P, Keckes J. Changes in the molecular orientation and tensile properties of uniaxially drawn cellulose films. Biomacromolecules 2006;7(11):3146-50.

[44] Gindl W, Keckes J. Drawing of self-reinforced cellulose films. J Appl Polym Sci 2007;103(4):2703-8.

[45] Duchemin BJC, Newman RH, Stainer MP. Structure-property relationship of all-cellulose composites. Compos Sci Technol 2009;69(7-8):1225-30.

[46] Beall GW. New conceptual model for interpreting nanocomposites behaviour. In: Pinnavaia TJ, Real GW, editors. Polymer-clay nanocomposites. Chichester: John Wiley and Sons; 2000. p. 267-80.
[47] Wiley JH, Atalla RH. Band assignments in the Raman-spectra of cellulose. Carbohyd Res 1987; 160:113-29.

[48] Gael JJ, Gardner KH, Koenig JL, Blackwell J. Infrared and Raman-spectroscopy of carbohydrates. 5. Normal coordinate analysis of cellulose-I. J Chem Phys 1975;62(3):1145-53.

[49] Edwards HGM, Farwell DW, Webster D. FT Ramen microscopy of untreated natural plant fibres. Spectrochim Acts Part a - Mol Biomol Spectrosc 1997;53(13):2383-92.

[50] Gierlinger N, Schwanninger M, Reinecke A, Burgert I. Molecular changes during tensile deformation of single wood fibers followed by Roman microscopy. Biomacromolecules 2006;7(7):2077-81.

[51] Atalla RH, Dimick BE. Raman-spectral evidence for differences between conformations of cellulose-I and cellulose-II. Carbohyd Res 1975;39(1):C1-3.

[52] Hamad WY, Eichhorn S. Deformation micromechanics of regenerated cellulose fibers using Roman spectroscopy. J Eng Mater Technol - Trans Asme 1997;119(3):309-13.

[53] Eichhorn SJ, Young RJ, Davies GR. Modeling crystal and molecular deformation in regenerated cellulose fibers. Biomacromolecules 2005;6(1):507-13.

[54] Kong K, Wilding MA, Ibbett RN, Eichhorn SJ. Molecular and crystal deformation of cellulose: uniform strain or uniform stress? Faraday Discuss 2008;139: 283-98. 